\title{
THE EFFECTS OF A SOCCER MATCH ON MUSCLE DAMAGE INDICATORS
}

\author{
Antonela Devrnja and Branka R. Matković \\ University of Zagreb, Faculty of Kinesiology, Zagreb, Croatia
}

Original scientific paper

https://doi.org/10.26582/k.50.1.15

UDC: $796.332: 591.175$

\begin{abstract}
:
During a soccer match players perform a substantial number of explosive activities such as jumps, duels, shots and dribblings, accelerations, decelerations, changes of direction and sprints. Precisely such repetitive eccentric contractions are related to muscle damage (exercise-induced muscle damage) that is, two or three days after the match, clinically presented as muscle soreness. The aim of this research was to identify the changes in muscle damage indicators in young players after playing a soccer game. The sample of examinees was composed of 43 soccer players ( $16.8 \pm 1.06$ years) who were divided into two groups according to their age (22 cadets aged $15.86 \pm 0.35$ years and 21 U19 players aged $17.76 \pm 0.54$ years). Each group played one soccer game lasting 90 minutes each. Right before and immediately after the soccer match, examinees' venous blood samples were taken in order to determine the markers of muscle damage. All statistical analyses were conducted by the SPSS software. The examinees demonstrated significantly higher values of myoglobin, creatine kinase, lactate dehydrogenase, aminotransferase, alkaline phosphatase and gamma-glutamyl-transferase after the game, as well as total number of leukocytes and concentration of C-reactive protein as indicators of inflammation. The results of this research showed that, as the muscle protein concentration was increased and an inflammatory reaction also occurred, soccer matches caused muscle damage in young players.
\end{abstract}

Key words: creatine kinase, leukocytes, male soccer players

\section{Introduction}

A soccer match lasts 90 minutes and is divided into two half-times of 45 minutes. Each half of a match can be prolongated for several minutes to make up for the overall number and duration of game interruptions (due to injured players treatments, rough fouls, etc.). There are also competitions, for example the World Cup or the European Championship, with specific rules that do not allow a tied final score in a game, so that extra time (overtime) is played, or even a penalty shootout is executed, which certainly adds to the overall load volume of players. During a soccer game players walk, run and sprint, either with or without the ball, moving forwards, backwards or sideways, while additional load is caused by jumps, shots, headers, duels, sudden accelerations or decelerations, and changes of direction. Depending on the rules, the dimensions of a soccer field can vary in length from 90 up to 120 meters, while its width can range between 45 and 90 meters. In terms of surface, players should cover an area of between $4,050 \mathrm{~m}^{2}$ up to $10800 \mathrm{~m}^{2}$, which means that during a game they cover a total of 8,000 to $13,000 \mathrm{~m}$, sometimes even more, while the goalkeeper aver- agely covers approximately 4,000 m (Bradley \& Noakes, 2013; Clemente, 2016; Sarmento, et al., 2014; Varley, et al., 2016).

During a soccer match players cover a total of 9 to $12 \mathrm{~km}$, where between 2 and $3 \mathrm{~km}$ are covered by high intensity running and nearly $0.5 \mathrm{~km}$ by sprints (Bradley, et al., 2009; Mohr, Krustrup \& Bangsbo, 2003; Mohr, et al, 2016). Each player performs between 1,000 and 1,400 short-term activities, with an average change of activity every 4 to $6 \mathrm{~s}$ (Mohr, et al., 2003). Research has also shown that players perform between 150 and 250 high intensity actions with significant differences in lactate results during a game, which indicates clear variations in energy supply for the mentioned activities (Krustrup, et al., 2006). Likewise, recovery intervals between such actions are often shorter than 72 seconds, which can have a negative effect on the subsequent efficiency of short-term activities, particularly on repeating sprints (Bradley, et al., 2009).

Furthermore, during a soccer match players perform a substantial number of explosive activities such as jumps, duels, shots and dribblings (Andersson, Ekblom \& Krustrup, 2008), accelerations, decelerations, changes of direction (COD) and 
sprints (Varley \& Aughey, 2013). It is precisely such repetitive eccentric contractions that are related to muscle damage (EIMD - exercise-induced muscle damage) (Mohr, et al., 2016; Nédélec et al., 2012), which is clinically presented as muscle soreness and developed two or three days after the match (DOMS - delayed onset of muscle soreness) (Fatourus, et al., 2010; Ispirlidis, et al., 2008). The EIMD is mostly a result of mechanical stress, imbalances in calcium levels and inflammatory responses with phagocyte infiltration, formation of free radicals, increase of cytokine concentration and other inflammatory parameters within the muscle (Fatourus, et al., 2010). The formation of reactive oxygen species can facilitate the reparation of damaged tissue through the process of phagocytosis and the neutrophil respiratory burst, however, high levels of reactive oxygen species can also damage vital structures in the cell, as well as lead to oxidative stress (Fatourus, et al., 2010; Ji, 2008).

The goal of this research was to identify the changes in muscle damage indicators in young players after a soccer game.

\section{Methods}

The sample of examinees was composed of 43 male soccer players (age $16.8 \pm 1.06$ years) who met the set inclusion criteria of having played no less than 10 matches and participating in at least $75 \%$ of practice sessions during the previous season, in addition to having at least 8 years of experience in playing soccer. The participants were divided into two groups according to their age: 22 of the participant were cadets (age $15.86 \pm 0.35$ years), while 21 were U19 players (age $17.76 \pm 0.54$ years). Two games of 90 minutes each were played on the soccer field of the Soccer Club Sesvete in Zagreb, both on the same day in November 2015. The first game, played by cadets, started at 10:15 a.m. and the second, played by juniors, at 12:30. During the first match the air temperature was between 2 and $4{ }^{\circ} \mathrm{C}$, air pressure was $1023 \mathrm{hPa}$ and the humidity was $92 \%$, whereas during the second game the mentioned parameters were $5^{\circ} \mathrm{C}, 1022 \mathrm{hPa}$ and $86 \%$, respectively.

During the weeks before the games all the players participated in the training process according to the scheduled plan and programme and they were all instructed not to modify their usual eating habits and activities, i.e. to make no changes in their training, eating and competition plan, as well as to refrain from consuming additional multivitamin supplements or antioxidants at least two weeks prior to the testing. During the games the players could drink only water as needed. Likewise, an agreement was made that all the starters would play all 90 minutes, with the exception in case of any injury, when a substitution would be allowed. The players were informed that those who did not play 90 minutes would be excluded from the research. To guarantee and motivate the players to make their best effort for official matches, and to provide a realistic physiological and psychological setting identical to the one during official competitions, the games were attended by the coach of the Soccer Club Sesvete, as well as by the head coach of the U16 and U18 national team.

The load during the games was measured by portable GPS devices (Catapult Innovations, Scoresby, Australia) with a $10 \mathrm{~Hz}$ data collection frequency in order to determine the distances that the players covered during the match. The GPS devices were placed in special vests that enabled the GPS device to be secured on the player's back, between the shoulder blades, without affecting the player's performance. Prior to placing the vests on the players, each of them got a Polar pulse meter (Polar Electro, Kempele, Finland), secured on their chest for monitoring players' heart rate (HR). In keeping with the instructions of the manufacturer, the GPS devices were activated 15 minutes before the testing, while after the completion of the game the data were transferred to a computer and analysed using the original Sprint 5.1. programme (Catapult Sports Pty Ltd, 2011). The reliability and accuracy of using a GPS device for game analysis has previously been confirmed in a series of research (Castellano, Casamichana, Calleja-Gonzalez, San Roman \& Ostojić, 2011; Mallo, Mena, Nevado \& Paredes, 2015).

Right before and immediately after the soccer match, venous blood samples were taken from 43 players (one examinee quited his participation before the second blood sample draw) to determine the following parameters: complete blood count (CBC), creatine kinase (CK), myoglobin (MYO), lactate dehydrogenase (LDH), aspartata aminotransferase (AST), alanine aminotransferase (ALT), gammaglutamyl-transferase (GGT), C-reactive protein (CRP). The blood sampling was conducted by three educated medical technicians in an adequate room located next to the soccer field and the examinees were seated during the blood sampling procedure. Their blood was taken from the antecubital vein in keeping with the recommendations of the Croatian Society of Medical Biochemistry and Laboratory Medicine (Nikolac, Šupak-Smolčić, Šimundić \& Ćelap, 2013) and two tubes of each sample were taken by using the following Vacuette ${ }^{\circledR}$ test tubes (Greiner Bio-One, Kremsmunster, Austria):

1) Z serum clot activator tube, $4 \mathrm{~mL}$ (a serum tube coated with a clot activator) - for determining CK, GGT, ALT, AST, CK, LDH, MYO, CRP;

2) K3E K3EDTA tube, $3 \mathrm{~mL}$ - for determining CBC.

Directly after the blood sampling, all blood samples were taken in a portable refrigerator from the soccer field to the Institute of Clinical Chemistry at the Clinical Hospital Centre "Sestre Milosrd- 
nice", Zagreb, where, immediately upon receipt, all the analysis were performed.

Complete blood count analysis was performed by the DxH 800 analyser (Beckman Coulter, Tokyo, Japan), whereas the erythrocyte sedimentation was conducted manually using the Westergren method. Routine biochemical parameters (CRP, ALP, GGT, ALT, AST, CK, LDH) were measured by the Architect c 8000 platform (Abbott Diagnostics, Chicago, USA) using general reagents. Measurements of myoglobin concentration in the serum were performed by the Architect i2000 immunochemical analyser (Abbott Diagnostics, Chicago, USA) using the Chemiluminescence test - CMIA (chemiluminescent microparticle immunoassay).

Quality control (QC) for routine biochemical parameters was carried by the Multichem S (Abbott Diagnostics, Chicago, USA), while quality control for MYO was determined by the Architect STAT Myoglobin controls and the Architect Ferritin controls.

The data was processed by descriptive statistical indicators applicable for the distribution of each individual variable - means, standard deviation and range between the minimum and maximum value for the normally distributed variables. The distribution normality of the tested variables was checked before statistical analysis by the visual inspection of histograms and graphs of normal probability distributions, as well as by the Shapiro-Wilks test. The data which did not follow normal distribution was first transformed by logarithmic transformation. In case the log transformation did not result in a distribution resembling normal distribution, nonparametric statistical tests were then used.

The dynamics of the changes in the values of muscle damage indicators at the examined timepoints (right before and immediately after the soccer game) was determined by the t-test for incremental sampling. All statistical analyses were conducted using the SPSS software (Stat-Soft Inc., Tulsa, OK, USA). The level of statistical significance was set at $\mathrm{p}<.05$.

This research was approved by the Ethical Committee of the School of Medicine, University of Zagreb. All the examinees, as well as their parents for those participants who were under the age of 18 at the time the research was conducted, filled out and signed a form which was composed according to the principles of the Declaration of Helsinki, which thus represented an informed consent form of participation in the research.

\section{Results}

General characteristics of the players are presented in Table 1. In total, there were 43 male soccer players, aged $16.80 \pm 1.10$ years on average (range from 15.00 to 19.00 years). Their body height was $181.0 \pm 7.00 \mathrm{~cm}$, body mass $71.0 \pm 6.00 \mathrm{~kg}$ and body mass index $21.70 \pm 1.50 \mathrm{~kg} / \mathrm{m}^{2}$. During the game they covered $107.20 \pm 9.20 \mathrm{~m} / \mathrm{min}$ on average.

The obtained results for creatine kinase and myoglobin were not normaly distributed so median and interquartile range were calculated (Table 2). The differences between pre- and post-game concentrations were tested by Wilcoxon matchedpair signed rank test used for dependent variables. The other variables, used as markers of muscle damage and inflammation, showed normal distribution, so means and standard deviations were calculated, as well as confidence interval. The significance of the pre- and post-game values were tested by t-test (Table 3 ). The average creatine kinase activity before the game was $215 \mathrm{U} / \mathrm{L}$ and it significantly increased after the match ( $336 \mathrm{U} / \mathrm{I})$, as well as the concentration of myoglobin $(32.7 \mathrm{ng} / \mathrm{mL}$ pregame vs. $148.8 \mathrm{ng} / \mathrm{mL}$ post-game).

Table 1. General characteristic of the examinees

\begin{tabular}{lccc}
\hline Variable & Mean \pm SD & Min & Max \\
\hline Age (years) & $16.80 \pm 1.10$ & 15.00 & 19.00 \\
Body height $(\mathrm{cm})$ & $181.00 \pm 7.00$ & 166.50 & 201.40 \\
Body mass $(\mathrm{kg})$ & $71.00 \pm 6.00$ & 60.80 & 84.10 \\
BMl $\left(\mathrm{kg} / \mathrm{m}^{2}\right)$ & $21.70 \pm 1.50$ & 17.60 & 25.20 \\
$\begin{array}{l}\text { Covered distances } \\
(\mathrm{m} / \mathrm{min})\end{array}$ & $107.20 \pm 9.20$ & 84.30 & 132.90 \\
\hline
\end{tabular}

Table 2. Changes in values of indirect muscle damage indicators

\begin{tabular}{lccc}
\hline Variable & $\begin{array}{c}\text { PRE-GAME } \\
\text { Median (IQR) }\end{array}$ & $\begin{array}{c}\text { POST-GAME } \\
\text { Median (IQR) }\end{array}$ & $\mathrm{p}$ \\
\hline $\begin{array}{l}\text { CK }(\mathrm{U} / \mathrm{L}) \\
\mathrm{MYO} \\
(\mathrm{ng} / \mathrm{mL})\end{array}$ & $215(124-412)$ & $336(245-635)$ & $<.001$ \\
\hline
\end{tabular}

Note. IQR=interquartile range; $p=$ value for the

Wilcoxon matched pair signed rank

$\mathrm{CK}=$ creatin kinase; $\mathrm{MYO}=$ myoglobin

\section{Discussion and conclusions}

Changes in the creatine kinase activity and levels of myoglobin and leukocytes are treated as effective indirect indicators of intensity during the game, however, even more as indicators of myocyte damage which occurred during a sports activity (Bessa, et al., 2016; Brancaccio, Maffulli \& Limongelli, 2007; Fatououros, et al., 2008; Mougios, 2007; Thorpe \& Sunderland, 2012). Due to the specific character of a soccer match, as players periodically perform very demanding activities interrupted by periods of jogging or walking, or even standing in place, in addition to numerous sudden CODs, and without neglecting to mention movements with the ball - which leads to high loads on active musculature - micro damage of muscle fibres occurs and, 
Table 3. Changes in values of indirect muscle damage indicators and inflammation

\begin{tabular}{lccccc}
\hline Variable & $\begin{array}{c}\text { PRE-GAME } \\
\text { Mean } \pm \text { SD }\end{array}$ & $\begin{array}{c}\text { POST-GAME } \\
\text { Mean } \pm S D\end{array}$ & $\begin{array}{c}\text { Mean of the pre- and } \\
\text { post-game difference }(\mathrm{Cl})\end{array}$ & T-test & $\mathrm{p}$ \\
\hline Leukocytes $\left(\times 10^{\wedge} \mathrm{g} / \mathrm{L}\right)$ & $6.32 \pm 1.22$ & $9.47 \pm 2.43$ & $-3.15(-3.84--2.46)$ & -9.17 & $<.001$ \\
AST $\left(\mathrm{U} / \mathrm{L} 37^{\circ} \mathrm{C}\right)$ & $24.26 \pm 8.43$ & $30.44 \pm 10.16$ & $-6.19(-7.24--5.13)$ & -11.82 & $<.001$ \\
ALT $\left(\mathrm{U} / \mathrm{L} 37^{\circ} \mathrm{C}\right)$ & $17.40 \pm 5.92$ & $18.12 \pm 6.51$ & $-0.72(-1.17--0.27)$ & -3.25 & $<.002$ \\
GGT $\left(\mathrm{U} / \mathrm{L} 37^{\circ} \mathrm{C}\right)$ & $13.81 \pm 3.67$ & $14.63 \pm 3.73$ & $-0.81(-1.14--0.49)$ & -5.07 & $<.001$ \\
LDH $\left(\mathrm{U} / \mathrm{L} 37^{\circ} \mathrm{C}\right)$ & $208.67 \pm 43.74$ & $261.86 \pm 60.04$ & $-53.19(-73.69--32.68)$ & -5.23 & $<.001$ \\
ALP $\left(\mathrm{U} / \mathrm{L} 37^{\circ} \mathrm{C}\right)$ & $135.84 \pm 60.21$ & $139.37 \pm 64.75$ & $-3.53(-5.66--1.41)$ & -3.36 & $<.001$ \\
CRP $(\mathrm{mg} / \mathrm{L})$ & $0.96 \pm 1.15$ & $0.94 \pm 1.10$ & $0.01(-0.02-0.05)$ & 0.77 & $<.050$ \\
\hline
\end{tabular}

Note. $\mathrm{Cl}=95 \%$ confidence interval

consequently, creatine kinase is thus released in addition to other proteins from the cytosol (Brancaccio, et al., 2007; Thorpe \& Sunderland, 2012). Any type of muscular activity, isometric or isotonic concentric, can result in muscle damage, however, it is a known fact that eccentric muscle activity has the strongest impact on the development of muscle damage. Eccentric muscle contractions are considerably present during a soccer match, and any type of landing, whether it is walking, running or a jump, is in relation with eccentric muscle activity. The development of muscle damage caused by physical activity has not yet been explained in its entirety (Schoenfeld, 2016); however, it is determined that the sarcolemma, sarcoplasmic reticulum and Z-lines are damaged, perhaps even the permeability of the sarcolemma is altered (Fatouros \& Jamurtas, 2016). All the above-mentioned leads to the conclusion that the muscle protein concentration is increased and an inflammatory reaction then also occurs.

Peak values of CK concentration in the serum occur some 24 hours to four days after physical activity and they even remain elevated over the following couple of days (Clarkson, Kearns, Rouzier, Rubin \& Thompson, 2006; Mougios, 2007). It is quite interesting to mention that the concentrations of $\mathrm{CK}$ and myoglobin can be elevated up to extremely high values after eccentric contractions $(\mathrm{CK}>10,000 \mathrm{IU} / \mathrm{L}$, myoglobin $>1,000 \mathrm{IU} / \mathrm{L})$ (Nosaka \& Clarkson, 1996; Nosaka, Lavender, Newton \& Sacco, 2003). Due to a larger muscle mass and regular, daily, practice, athletes have higher CK values even at rest when compared to the population that does not engage in regular physical activity (Brancaccio, et al., 2007; Nikolaidis, et al., 2003); however, after being exposed to a test of equally demanding intensity, athletes shall demonstrate a lower increase of $\mathrm{CK}$ value in relation to a healthy inactive control group (Brancaccio, et al., 2007; Karamizrak, Ergen, Töre \& Akgün, 1994). Research have shown that the reaction of muscle damage indicators decreases as a result of frequent explosion to eccentric load, better yet, as a result of sports practice (Chen \& Hsieh, 2000).
In this research the recorded CK values before the soccer match $(291.88 \mathrm{U} / \mathrm{L})$ were somewhat higher than expected, however consistent with the research of Silva, Rebelo et al. (2013) (300.6 U/L) and Rampinini et al. (2011) (310 U/L). Heisterberger et al. (2013) concluded that professional soccer players show CK values above the normal upper limit on a daily basis when compared with normal, or better to say, not as much physically active population. Due to the long-term retention of CK in the serum, the measured values of CK should be examined in relation to the activities that have preceded the measurement. As the examinees played an official soccer match three days before the testing and then continued with their regular daily practice, somewhat higher enzyme values measured before the match might be residual indicators of muscle damage due to previous activities (McLellan, Lovell \& Gass, 2010). Brancaccio et al. (2007) indicate that CK values should be interpreted with caution because of numerous factors which are interconnected with different CK values at rest, such as age, gender, race, muscle mass, or level of physical activity. In addition, some athletes react to physical activity with smaller increases in the level of enzymes - low responders, whereas others respond with greater increases in enzyme levels high responders.

Statistically significant increases in CK values in the serum (median difference $=-121 ; \mathrm{p}<.001$ ) after the match when compared to the values before the game are also in compliance with the results of numerous other research, as well as the determined correlation between the changes in $\mathrm{CK}$ values and intensity during the soccer game, i.e., the fatigue index $\left(\mathrm{R}_{\mathrm{s}}=.38 ; \mathrm{p}=.01\right)$, covered distance $\left(\mathrm{R}_{\mathrm{s}}=.38\right.$; $\mathrm{p}=.01)$ and the percentage of dwelling time in running at the speed between $12-16 \mathrm{~km} / \mathrm{h}\left(\mathrm{R}_{\mathrm{s}}=.37 ; \mathrm{p}=.02\right)$ and at the speed above $16 \mathrm{~km} / \mathrm{h}\left(\mathrm{R}_{\mathrm{s}}=.37 ; \mathrm{p}=.02\right)$. McLellan et al. (2010) found that participating in a rugby match results in a significant increase in CK after the game, presumably due to the occurrence of muscle damage. A pronounced increase in CK values (seven times higher) after playing a soccer 
game was also registered by Fatouros et al. (2008), which indirectly points to the occurrence of muscle microtrauma during the soccer match. The occurrence of muscle microtrauma has been related to numerous repetitive intermittent intensive eccentric actions such as running and jumping, as well as to frequent sudden accelerations and decelerations which are an integral part of this sports activity. In addition, Osgnach, Poser, Bernardini, Rinaldo, and Di Prampero (2010) suggest in their research that increased metabolic demands and a higher level of overall energy consumption during a game and/or training session appear due to the acceleration and deceleration activities of soccer players in connection with COD, which then results in elevated values of mechanical and metabolic stress. Ispirlidis and associates (2008) also discovered an increase in CK values immediately after playing a soccer match. They interpreted the arising muscle damage as a result of numerous repetitive eccentric contractions during the match, as well as of physical contacts between players, and of contacts with the ball, which can potentially generate inflammatory responses during the game.

Mougios (2007) examined the changes in CK values of athletes over a period of ten years and determined that the highest values of CK were up to three times higher in soccer players than in swimmers. The reason for such a difference in the maximum values of $\mathrm{CK}$ was interpreted by the nature of the sport in question, i.e., as a result of numerous eccentric contractions, sudden CODs, jumps, duels and other types of impulsive action that were part of soccer matches and practices, as well as due to the long duration (no less than 90 minutes), extremely demanding games in terms of energy consumption which were occasionally played in extremely harsh weather conditions and on different surfaces that are not always ideal.

Although the values of creatine kinase are considered as indirect muscle damage indicators, Silva, Ascensão et al. (2013) have indicated that the increase of enzyme values in the serum can also occur as a result of temporary alterations in the permeability of the membrane, i.e., that there are potentially certain other mechanisms that could account for the presence of cytoplasmic enzymes in the serum after physical activity, such as changes in the cellular energy production processes (Baird, Graham, Baker \& Bickerstaff., 2012) for example. Findings by Nedelec et al. (2012) and Silva, Ascensão et al. (2013) confirm the above-mentioned theory as they point out an increase of enzyme values in the serum, yet, with no impairment of muscle strength and efficiency. Upon considering all the known facts and the daily occurrence of new insights, the values of $\mathrm{CK}$, as well as any changes due to physical activity, should be critically examined and interpreted. However, the conclusion can be made that the increase of CK in the serum is a natural and normal response to physical activity (Baird, et al., 2012).

Myoglobin is one of three types of globin found in the human organism (in addition to haemoglobin and neuroglobin). It can primarily be found in cardiac and skeletal muscle cells, while the highest concentrations are measured in slow oxidative fibres type I. Myoglobin is also present in fasttwitch muscle fibres, even in the fastest type IIx. Naturally, the faster the fibres are, i.e., in case the fibres are more of an anaerobic character, the level of myoglobin reduces. It was first described as a compound that functions as an oxygen storage unit in muscle cells and that can be used, for example, when there is a sudden increase in oxygen demand during physical activity. Meanwhile, its role in physical activity does not cease at this point (Pittman, 2016), as myoglobin also has the function of facilitating oxygen diffusion within muscle cells, especially during muscle contraction, and thereby of ensuring almost identical values of oxygen pressure in all parts of the muscle cell (Wittenberg $\&$ Wittenberg, 2003). In cases of muscle damage being a result of physical activity, damaged cells can develop oxygen deficiency due to myoglobin release from the cytosol into the circulation (Cui \& Jiang, 2016). In addition, it is presumed that myoglobin also has a role in the regulation of nitrogen oxide (NO) in the muscle tissue, as well as in the process of microcirculation (Brancaccio, et al., 2010).

Extreme load, such as running a marathon, can generate an increase in myoglobin concentration in the plasma even up to 19 times (Ohman, et al., 1982). As the half-life of myoglobin is only 2-3 hours, its values are normalized relatively quickly, as fast as after 6-8 hours. Hasenoehrl and associates (2016) thus subjected 15 healthy students to intensive eccentric contractions of the forearm flexors which resulted in muscle damage. However, even though the myoglobin concentration was increased, the values were not statistically significant. In another research conducted with well-trained triathlon athletes, their myoglobin was increased immediately after the race, but it remained high even several days later. The authors concluded that the reason for such values was probably a mild inflammation, as well as the fact that the examinees immediately continued with their regular training process (Neubauer, Konig, \& Wagner, 2008). Magalhães et al. (2010) identified an increase in myoglobin concentration 30 minutes after the match in young soccer players; however, 24 hours later the measured values returned to their normal level.

The examinees of our research, in keeping with what was expected as their myoglobin level was measured immediately after the game, demonstrated significantly higher values of myoglobin (from $37.38 \pm 15.87 \mathrm{ng} / \mathrm{mL}$ to $196.17 \pm 133.73 \mathrm{ng} / \mathrm{mL}$ ). 
During this research, similar results were also recorded for other enzymes that are released from active muscles and are used as indirect indicators of muscle damage caused by physical activity. All examinees demonstrated a slight or greater increase in the measured values, however statistically insignificant. As part of this research, the following parameters were also measured: lactate dehydrogenase, aminotransferase (aspartate aminotransferase, alanine aminotransferase), alkaline phosphatase and gamma-glutamyl-transferase. The results of this research are in accordance with a series of studies that have previously examined muscle damage caused by physical activity. Most studies demonstrated an increase of CK and LHD, as well as of other measured enzymes.

Machado, Rebelo, Oliveira, Silva, Marques, and Ascensão (2009) recorded a significant increase of LDH, CK, AST and ALT in 15 professional soccer players right after the game. Similar results were also recorded by Bezzera and associates (2014) during a research with Brazilian soccer players and the conclusion was made that a soccer match is a sufficiently aggressive activity for the occurrence of muscle damage. On a sample composed of 12 soccer players, Celenk, Akil, and Kara (2013) also examined the effects of a soccer game lasting 90 minutes on muscle damage indicators. They determined that enzyme concentrations increased already during the game, while after the match there was a significant increase of creatine kinase - MB isoenzyme $\left(\mathrm{CK}^{\mathrm{MB}}\right)$. $\mathrm{LDH}, \mathrm{CK}$ and $\mathrm{AST}$ also increased, however not in a statistically significant amount, while the ALT and GGT concentrations remained unaltered. Already 24 hours after the match, all the measured values but $\mathrm{CK}$ returned to baseline, so the authors concluded that was a result of adaptation to the soccer practice.

A comparison with some other sports games is quite interesting. McLellan et al. (2011) monitored the CK level after a rugby game, which is without a doubt a demanding and intensive sports game. They determined a significant increase of CK immediately after the game, and such high levels were maintained unchanged even during five rest days. It is especially interesting that they established a significant correlation between the level of CK and the number of players' collisions. On the other hand, Takahashi et al. (2007) only recorded an increase of LDH in their study with rugby players, while CK, AST and ALT values remained unchanged during 10 minutes after the game. In a study with young basketball players, 19-year-olds, Montgomery and associates (2008) determined an increase of CK and myoglobin after the game; however, they concluded that, when compared with the data found in literature, such an increase was not as substantial as the one caused only by eccentric contractions. An increase of CK and myoglobin was also measured immediately after a simulated badminton match which lasted 45 minutes (Abián Vicén, 2015). However, despite the elevated values of muscle damage indicators, there was no indication of the decline in badminton specific motor performance, thus the authors concluded that the resulting damage was of weak intensity.

Souglis, Bogdanis, Giannopoulou, Papadopoulos, and Apostolidis (2015) analysed the effects of competitive games on muscle damage indicators in four different sports games - soccer, basketball, handball and volleyball. CK and LDH levels were monitored before and immediately after the match and it was determined that all athletes demonstrated a significant increase in the concentration of the measured enzymes. Most notable differences were recorded in soccer players as their level of CK was twice or three times as high as it was in athletes from other sports. Volleyball players showed the lowest values of both enzymes after the game. The recorded differences are the result of different durations of the matches, as well as of unequal play intensities. Thus, for example, during a soccer game players cover distances three to four times longer than the ones covered in basketball or handball, by high-intensity running. In addition, it was recorded that $\mathrm{CK}$ values returned to the level measured before the game already 37 hours after the match, which was not in accordance with the findings published by Ispirlidis et al. (2008) with soccer players and by Chatzinikolaou, Draganidis et al. (2014) with basketball players where the maximum $\mathrm{CK}$ values were not recorded until 48 hours after the game. The authors believe that the mentioned differences are related to the competitive level of the tested athletes, which was higher in their research, as well as to the recovery methods which were consequently also at a higher level.

Petterson and associates (2008) subjected a group of 15 active men to a one-hour weight lifting practice. They measured clinical parameters immediately before and after the practice. Their study recorded significant increases of CK, LDH, AST, ALT and myoglobin, while ALP, GGT and bilirubin remained unchanged. The authors underline the importance of knowing the level of the examinees' usual physical activity, as well as intensity, type and duration of the physical activity that was potentially implemented at least one week before the analysis of muscle damage indicators due to the possibility of misinterpreting the measured values.

Hammouda et al. (2012) analysed the effects of one-time anaerobic activity (30-second Wingate test) on muscle damage indicators in young soccer players (17.5 \pm 0.4 years). They determined that even such a short-term activity was quite sufficient to generate an increase of the monitored indicators (CK, LDH, AST, ALT). 
Kratz et al. (2002) conducted a very extensive research on the changes in hematomic and biochemical laboratory changes of marathon athletes before and after the race. They determined an increase of aminotransferases within four hours after the race and 24 hours after. The alterations of AST were statistically significant, while the increase of ALT concentration, an enzyme which is surely more an indicator of liver damage, even though it is also present in skeletal muscles in smaller quantities, showed no statistically significant difference. The values of alkaline phosphatase, creatine kinase and myoglobin also demonstrated a substantial increase. The conclusion was made that the obtained results indicated the occurrence of muscle damage due to intensive load and consequently also due to the enzymes which were released into the circulation. Most of the existing research demonstrated that AST and ALT concentrations were related to the intensity and duration of the activity (Chamera et al., 2014. Lippi et al., 2011; Nagel, Seiler, Franz \& Jung, 1990; Shin, Park, Ahn, Park \& Kim, 2016).

Studies with ultramarathon athletes who completed the Western States Endurance Run of a total of $161 \mathrm{~km}$, which besides running also included a considerable load in relation to the environment (difference in altitude, temperature fluctuations) demonstrated a significant increase of muscle damage indicators (CK, myoglobin, AST, ALT) (Kupchak, Kraemer, Hoffman, Phinney, \& Volek, 2014). The measured values remained elevated even after two days (except for myoglobin which returned to its pre-race values within 24 hours) so that the authors concluded that an ultramarathon race causes very extensive muscle damage.

Intense eccentric muscle activity results in muscle damage which is followed by an inflammatory response (Cornish \& Johnson, 2014; Crameri, et al., 2007; Malm \& Yu, 2012; Philippou, et al., 2009; Proske \& Allen, 2005). Schoenfeld (2016) presumed that the body's response to muscle damage can be identified by a reaction to an infection. Namely, after an eccentric activity neutrophils migrate towards the point of damage, while substances released from the damaged myofibers attract macrophages towards that point.

Previous research has shown that the number of leukocytes increases both during and after physical activity (Hammouda, et al., 2012; Ihalainen, et al., 2013; Neves, et al., 2015; Rosado, 2016). Usually all subtypes of leukocytes are represented in the mentioned increase, from neutrophils (Ferrer, Tauler, Sureda, Tur, \& Pons, 2009; Morgado, et al., 2016), monocytes (Gomes \& Florida-James, 2016) to lymphocytes (Kakanis, Peake, Hooper, Gray, \& Marshall-Gradisnik, 2010) but they were then reduced, for example after a marathon (Shin \& Lee, 2013), whereas the values of eosinophils remained unaltered or declined (Kakanis, et al., 2010).
Kendall, Hoffman-Goetz, Houston, MacNeil, and Arumugam (1990) revealed that acute responses of leukocytes to physical activity depend on the duration, intensity and type of activity, as numerous other authors later confirmed (Neves, et al., 2015). As for the increase of neutrophils, there are various factors which are responsible. The greatest contribution primarily results from the increase of adrenaline and noradrenaline concentrations, which is usually associated with physical activity, and which is later accompanied by an increase of cortisol concentration, which at the same time has a long-term effect. In this way the mentioned factors mobilise the neutrophils from the bone marrow and are the cause for the maintaining of a higher neutrophil concentration even several hours after the activity (Gomes \& Florida-James, 2016). Here it must be said that catecholamines increase cardiac output and open capillaries in order to amplify blood flow towards the active skeletal muscles, which then causes a mechanical demarginalization of leukocytes and an increase in their number in the peripheral blood. They are also responsible for the release of leukocytes from the spleen, lungs or lymphatic tissues (Gomes \& Florida-James, 2016). It must be pointed out that moderate physical activity also induces changes in the function of neutrophils in the sense of improving their capacity for phagocytosis and the process of chemotaxis (Ortega, et al., 2005).

After the 90-minute match, an increase of the overall number of leukocytes was determined in our examinees, which is mainly related to the considerable increase of neutrophils; that is in accordance with most of the previous research conducted with soccer players, as well as with athletes from other sports games (Bessa, et al., 2016; Chatzinikolau, Draganidis, et al., 2014; Chatzinikolau, et al., 2014; Magalhães, et al., 2010). On the other hand, the number of lymphocytes reduced, which was also evident in the significant increase of the neutrophil-to-lymphocyte ratio (Malm, et al., 2004). The mentioned neutrophil-to-lymphocyte ratio (NLR) is a simple indicator that is, among other things, used as a predictor, i.e., indicator of inflammation (Forget, et al., 2017) as its normal values are in the range between 0.78 to 3.58 , which means that after the match our examinees were averagely right at the upper limit value of this index, i.e., at the border of developing inflammation. In addition, as there was no increase in the level of lymphocytes, the assumption can be made that in young soccer players the increase of neutrophils is related to the inflammatory nature of muscle damage. Findings of research on inflammation and muscle damage are not consistent; however, there is growing evidence that neutrophils infiltrate in the damaged muscle (Schneider \& Tiidus, 2007; Tidball, 2005). Although this may be positive from the viewpoint of muscle recovery and potential muscle adapta- 
tion (Tidball, 2005), this can also induce further inflammation and damage in the muscle, partially even through the formation of reactive compounds (König, et al, 2007).

The C-reactive protein belongs to the group of inflammation indicators. It is related to serious conditions such as cardiovascular diseases, diabetes or depression (Ansar \& Gosh, 2016). This protein is released from the liver under the influence of IL-6 (Fischer, 2006) and it is responsible for identifying and removing damaged cells. There is growing data that physical activity reduces CRP concentration i.e., that higher levels of physical activity and physical fitness reduce CRP from 6 to $35 \%$ (Plaisance \& Grandjean, 2006). Most of the research was conducted on adult populations (Fedewa, Hathaway, \& Ward-Ritacco, 2016); however, Sabiston et al. (2010) also managed to demonstrate this relation with physical activity in adolescent boys (between 13 and 16 years), but not in adolescent girls. According to this research, the soccer match generated a minimum reduction of CRP values (significant at the level of $p<.05$ ). The previously mentioned research by Souglis and associates (2015) that included soccer, basketball, volleyball and handball players presented somewhat different results and demonstrated the presence of an inflammatory response in players of all four sports games, after the game. The highest increase of CRP was recorded in soccer players, which the authors explained by a longer duration of the soccer match and greater distances covered. They otherwise determined that the changes in CRP after the games were similar to the ones published in previous studies with soccer players (Ispirlidis, et al., 2008), handball players (Chatzinikolaou, et al., 2014) and basketball players (Chatzinikolaou, Draganidis, et al., 2014). Their CRP values returned to baseline a day after the played matches.

The aim of this research was to present the effects of a soccer match on changes in the values of muscle damage indicators. As our examinees had a demanding schedule of practices and games for years, the mentioned effect was analysed within the existing frame of their schedule with no additional influence on their usual activities. This provided results indicating an objective representation of the effects of a soccer match on muscle damage indicators.

In the future, it would be interesting to study the values of the measured parameters up to several days after the game, as there are numerous research showing that there are significant changes in subsequent periods of time, i.e., during the recovery from the activity, or perhaps even to monitor the changes in muscle damage indicators throughout an entire season.

Children and adolescents who choose to be highly committed to any sport from an early age quickly become aware of all the advantages and disadvantages that are part of such a lifestyle. It is precisely for this reason that it is important to produce an effective mechanism for evaluating the effects of such a lifestyle on their health, as it might play a preventive role when it comes to sports injuries.

\section{References}

Abián Vicén, P. (2015). Análisis de la estructura del juego y parámetros morfológicos y fisiológicos en bádminton. [Analysis of the structure of the game and morphological and physiological parameters in badminton. In Spanish.] Doctoral dissertation, Polytechnic University of Madrid, School of Physical Activity and Sport Sciences (INEF), Madrid, Spain.

Andersson, H., Ekblom, B., \& Krustrup, P. (2008). Elite football on artificial turf versus natural grass: Movement patterns, technical standards, and player impressions. Journal of Sports Sciences, 26(2), 113-122.

Ansar, W., \& Ghosh, S. (2016). C-reactive protein: A clinical marker in cardiovascular disease. In Biology of C reactive protein in health and disease (pp. 143-165). New Delhi: Springer.

Ascensão, A., Rebelo, A., Oliveira, E., Marques, F., Pereira, L., \& Magalhães, J. (2008). Biochemical impact of a soccer match-Analysis of oxidative stress and muscle damage markers throughout recovery. Clinical Biochemistry, 41(10), 841-851.

Baird, M.F., Graham, S.M., Baker, J.S., \& Bickerstaff, G.F.(2012). Creatine-kinase and exercise-related muscle damage implications for muscle performance and recovery. Journal of Nutrition and Metabolism, 960363. doi: $10.1155 / 2012 / 960363$

Bessa, A.L., Oliveira, V.N., Agostini, G.G., Oliveira, R.J., Oliveira, A.C., White, G.E., ... \& Espindola, F.S. (2016). Exercise Intensity and Recovery: Biomarkers of Injury, Inflammation, and Oxidative Stress. Journal of Strength and Conditioning Research, 30(2), 311-319.

Bezerra, J.A., Silva, R.P.M., Jácome, J.G., Costa, J.M M., Melo, S.V.A., \& dos Santos, J.A.R. (2014). Respostas de biomarcadores musculares a uma partida de futebol. [Response of biomarkers to soccer match. In Portuguese.] RBFF-Revista Brasileira de Futsal e Futebol, 6(19), 9. 
Bradley, P.S., \& Noakes, T.D. (2013). Match running performance fluctuations in elite soccer: Indicative of fatigue, pacing or situational influences?. Journal of Sports Sciences, 31(15), 1627-1638.

Bradley, P.S., Sheldon, W., Wooster, B., Olsen, P., Boanas, P., \& Krustrup, P.(2009). High-intensity running in English FA Premier League soccer matches. Journal of Sports Sciences, 27(2), 159-168.

Brancaccio, P., Lippi, G., \& Maffulli, N. (2010). Biochemical markers of muscular damage. Clinical Chemistry and Laboratory Medicine, 48(6), 757-767.

Brancaccio, P., Maffulli, N., \& Limongelli, F.M. (2007). Creatine kinase monitoring in sport medicine. British Medical Bulletin, 81(1), 209.

Castellano, J., Casamichana, D., Calleja-González, J., San Román, J., \& Ostojic, S.M. (2011). Reliability and accuracy of 10 GPS devices for short-distance exercise. Journal of Sports Science and Medicine, 10, 233-234.

Celenk, C., Akil, M., \& Kara, E. (2013). The level of damage caused by football matches on players. Life Science Journal, 10(2), 2836-2839.

Chamera, T., Spieszny, M., Klocek, T., Kostrzewa-Nowak, D., Nowak, R., Lachowicz, M., ... \& Cieszczyk, P. (2014). Could biochemical liver profile help to assess metabolic response to aerobic effort in athletes?. Journal of Strength and Conditioning Research, 28(8), 2180-2186.

Chatzinikolaou, A., Christoforidis, C., Avloniti, A., Draganidis, D., Jamurtas, A.Z., Stampoulis, T., ... \& Fatouros, I.G. (2014). A microcycle of inflammation following a team handball game. Journal of Strength and Conditioning Research, 28(7), 1981-1994.

Chatzinikolaou, A., Draganidis, D., Avloniti, A., Karipidis, A., Jamurtas, A.Z., Skevaki, C.L., ... \& Papassotiriou, I. (2014). The microcycle of inflammation and performance changes after a basketball match. Journal of Sports Sciences, 32(9), 870-882.

Chen, T.C., \& Hsieh, S.S. (2000). The effects of repeated maximal voluntary isokinetic eccentric exercise on recovery from muscle damage. Research Quarterly for Exercise and Sport, 71(3), 260-266.

Clarkson, P.M., Kearns, A.K., Rouzier, P., Rubin, R., \& Thompson, P.D. (2006). Serum creatine kinase levels and renal function measures in exertional muscle damage. Medicine and Science in Sports and Exercise, $38(4), 623$.

Clemente, F.M. (2016). Physiological demands of the soccer and time--motion profile. In Small-sided and conditioned games in soccer training (pp. 15-25). Singapore: Springer.

Cornish, S.M., \& Johnson, S.T. (2014). Systemic cytokine response to three bouts of eccentric exercise. Results in Immunology, 4, 23-29.

Crameri, R.M., Aagaard, P., Qvortrup, K., Langberg, H., Olesen, J., \& Kjær, M. (2007). Myofibre damage in human skeletal muscle: Effects of electrical stimulation versus voluntary contraction. Journal of Physiology, 583(1), 365-380.

Cui, T., \& Jiang, M.S. (2016). Myoglobin A79G polymorphism association with exercise-induced skeletal muscle damage. Genetics and Molecular Research, 15(2), gmr:15027505.

Fatouros, I.G., Chatzinikolaou, A., Douroudos, I.I., Nikolaidis, M.G., Kyparos, A., Margonis, K., ... \& Mandalidis, D. (2010). Time-course of changes in oxidative stress and antioxidant status responses following a soccer game. Journal of Strength and Conditioning Research, 24(12), 3278-3286.

Fatouros, I.G., Chatzinikolaou, A., Ispirlidis, I., Jamurtas, A.Z., Nikolaidis, M.G., Michailidis, I., ... \& Taxildaris, K. (2008). Time-course of changes in inflammatory and performance responses following a soccer game. Medicine and Science in Sports and Exercise, 40(5), S432.

Fatouros, I.G., \& Jamurtas, A.Z. (2016). Insights into the molecular etiology of exercise-induced inflammation: Opportunities for optimizing performance. Journal of Inflammation Research, 9, 175.

Fedewa, M.V., Hathaway, E.D., \& Ward-Ritacco, C.L. (2016). Effect of exercise training on C reactive protein: a systematic review and meta-analysis of randomised and non-randomised controlled trials. British Journal of Sports Medicine, 51(8), published ahead of print. doi: 10.1136/bjsports2016-095999

Ferrer, M.D., Tauler, P., Sureda, A., Tur, J.A., \& Pons, A. (2009). Antioxidant regulatory mechanisms in neutrophils and lymphocytes after intense exercise. Journal of Sports Sciences, 27(1), 49-58.

Fischer, C.P. (2006). Interleukin-6 in acute exercise and training: What is the biological relevance. Exercise Immunology Review, 12, 6-33.

Forget, P., Khalifa, C., Defour, J.P., Latinne, D., Pel, M.C., \& Kock, M. (2017). What is the normal value of the neutrophilto-lymphocyte ratio?. BMC Research Notes, 10(1), 12.

Gomes, E.C., \& Florida-James, G. (2016). Exercise and the immune system. In Environmental influences on the immune system (pp. 127-152). Vienna: Spriger.

Hammouda, O., Chahed, H., Chtourou, H., Ferchichi, S., Miled, A., \& Souissi, N. (2012). Morning-to-evening difference of biomarkers of muscle injury and antioxidant status in young trained soccer players. Biological Rhythm Research, 43(4), 431-438.

Hasenoehrl, T., Wessner, B., Tschan, H., Vidotto, C., Crevenna, R., \& Csapo, R. (2016). Eccentric resistance training intensity may affect the severity of exercise induced muscle damage. The Journal of Sports Medicine and Physical Fitness, 57(9), 1159-1204. 
Heisterberg, M.F., Fahrenkrug, J., Krustrup, P., Storskov, A., Kjær, M., \& Andersen, J.L. (2013). Extensive monitoring through multiple blood samples in professional soccer players. Journal of Strength and Conditioning Research, 27(5), 1260-1271.

Ihalainen, J., Walker, S., Paulsen, G., Häkkinen, K., Kraemer, W.J., Hämäläinen, M., ... \& Mero, A.A. (2014). Acute leukocyte, cytokine and adipocytokine responses to maximal and hypertrophic resistance exercise bouts. European Journal of Applied Physiology, 114(12), 2607-2616.

Ispirlidis, I., Fatouros, I.G., Jamurtas, A.Z., Nikolaidis, M.G., Michailidis, I., Douroudos, I., ... \& Alexiou, V. (2008). Time-course of changes in inflammatory and performance responses following a soccer game. Clinical Journal of Sport Medicine, 18(5), 423-431.

Ji, L.L. (2008). Modulation of skeletal muscle antioxidant defense by exercise: Role of redox signaling. Free Radical Biology and Medicine, 44(2), 142-152.

Kakanis, M., Peake, J., Hooper, S., Gray, B., \& Marshall-Gradisnik, S. (2010). The open window of susceptibility to infection after acute exercise in healthy young male elite athletes. Journal of Science and Medicine in Sport, 13, e85-e86.

Karamizrak, S.O., Ergen, E., Töre, I.R., \& Akgün, N. (1994). Changes in serum creatine kinase, lactate dehydrogenase and aldolase activities following supramaximal exercise in athletes. Journal of Sports Medicine and Physical Fitness, 34(2), 141-146.

Kendall, A.D., Hoffman-Goetz, L.A., Houston, M.I., MacNeil, B., \& Arumugam, Y. (1990). Exercise and blood lymphocyte subset responses: Intensity, duration, and subject fitness effects. Journal of Applied Physiology, 69(1), 251-260.

König, D., Neubauer, O., Nics, L., Kern, N., Berg, A., Bisse, E., \& Wagner, K.H. (2007). Biomarkers of exercise-induced myocardial stress in relation to inflammatory and oxidative stress. Exercise Immunology Review, 13(1), 15-36.

Koutedakis, Y., Raafat, A., Sharp, N.C., Rosmarin, M.N., Beard, M.J., \& Robbins, S.W. (1993). Serum enzyme activities in individuals with different levels of physical fitness. Journal of Sports Medicine and Physical Fitness, 33(3), 252-257.

Kratz, A., Lewandrowski, K.B., Siegel, A.J., Chun, K.Y., Flood, J.G., Van Cott, E.M., \& Lee-Lewandrowski, E. (2002). Effect of marathon running on hematologic and biochemical laboratory parameters, including cardiac markers. American Journal of Clinical Pathology, 118(6), 856-863.

Krustrup, P., Mohr, M., Steensberg, A., Bencke, J., Kjær, M., \& Bangsbo, J. (2006). Muscle and blood metabolites during a soccer game: Implications for sprint performance. Medicine and Science in Sports and Exercise, 38(6), $1165-1174$.

Kupchak, B.R., Kraemer, W.J., Hoffman, M.D., Phinney, S.D., \& Volek, J.S. (2014). The impact of an ultramarathon on hormonal and biochemical parameters in men. Wilderness and Environmental Medicine, 25(3), 278-288.

Lippi, G., Schena, F., Montagnana, M., Salvagno, G.L., Banfi, G., \& Guidi, G.C. (2011). Significant variation of traditional markers of liver injury after a half-marathon run. European Journal of Internal Medicine, 22(5), e36-e38.

Machado, M., Breder, A.C., Ximenes, M.C., Simões, J.R., \& Vigo, J.F.F. (2009). Caffeine supplementation and muscle damage in soccer players. Brazilian Journal of Pharmaceutical Sciences, 45(2), 257-261.

Magalhães, J., Rebelo, A., Oliveira, E., Silva, J.R., Marques, F., \& Ascensão, A. (2010). Impact of Loughborough Intermittent Shuttle Test versus soccer match on physiological, biochemical and neuromuscular parameters. European Journal of Applied Physiology, 108(1), 39.

Mallo, J., Mena, E., Nevado, F., \& Paredes, V. (2015). Physical demands of top-class soccer friendly matches in relation to a playing position using global positioning system technology. Journal of Human Kinetics, 47(1), 179-188.

Malm, C., Sjödin, B., Sjöberg, B., Lenkei, R., Renström, P., Lundberg, I.E., \& Ekblom, B. (2004). Leukocytes, cytokines, growth factors and hormones in human skeletal muscle and blood after uphill or downhill running. Journal of Physiology, 556(3), 983-1000.

McLellan, C.P., Lovell, D.I., \& Gass, G.C. (2011). Biochemical and endocrine responses to impact and collision during elite rugby league match play. Journal of Strength and Conditioning Research, 25(6), 1553-1562.

Mohr, M., Draganidis, D., Chatzinikolaou, A., Barbero-Álvarez, J.C., Castagna, C., Douroudos, I., ... \& Jamurtas, A.Z. (2016). Muscle damage, inflammatory, immune and performance responses to three football games in 1 week in competitive male players. European Journal of Applied Physiology, 116(1), 179-193.

Mohr, M., Krustrup, P., \& Bangsbo, J. (2003). Match performance of high-standard soccer players with special reference to development of fatigue. Journal of Sports Sciences, 21(7), 519-528.

Montgomery, P.G., Pyne, D.B., Cox, A.J., Hopkins, W.G., Minahan, C.L., \& Hunt, P.H. (2008). Muscle damage, inflammation, and recovery interventions during a 3-day basketball tournament. European Journal of Sport Science, 8(5), 241-250.

Morgado, J.P., Matias, C.N., Monteiro, C.P., Alves, F., Reis, J.F., Santos, D.A., ... \& Sardinha, L.B. (2016). Comparison of immunohematological profile between endurance and power-oriented elite athletes. Applied Physiology, Nutrition, and Metabolism, 42(3), 257-262. 
Mougios, V. (2007). Reference intervals for serum creatine kinase in athletes. British Journal of Sports Medicine, 41(10), 674-678.

Nagel, D., Seiler, D., Franz, H., \& Jung, K. (1990). Ultra-long-distance running and the liver. International Journal of Sports Medicine, 11(06), 441-445.

Nédélec, M., McCall, A., Carling, C., Legall, F., Berthoin, S., \& Dupont, G. (2012). Recovery in soccer. Sports Medicine, 42(12), 997-1015.

Neubauer, O., König, D., \& Wagner, K.H. (2008). Recovery after an Ironman triathlon: Sustained inflammatory responses and muscular stress. European Journal of Applied Physiology, 104(3), 417-426.

Neves, P.R.D.S., Tenório, T.R.D.S., Lins, T.A., Muniz, M.T.C., Pithon-Curi, T.C., Botero, J.P., \& Do Prado, W.L. (2015). Acute effects of high-and low-intensity exercise bouts on leukocyte counts. Journal of Exercise Science and Fitness, 13(1), 24-28.

Nikolac, N., Šupak-Smolčić, V., Šimundić, A.M., \& Ćelap, I. (2013). Croatian Society of Medical Biochemistry and Laboratory Medicine: National recommendations for venous blood sampling. Biochemia Medica, 23(3), $242-254$.

Nikolaidis, M.G., Protosygellou, M.D., Petridou, A., Tsalis, G., Tsigilis, N., \& Mougios, V. (2003). Hematologic and biochemical profile of juvenile and adult athletes of both sexes: implications for clinical evaluation. International Journal of Sports Medicine, 24(07), 506-511.

Nosaka, K., \& Clarkson, P.M. (1996). Changes in indicators of inflammation after eccentric exercise of the elbow flexors. Medicine and Science in Sports and Exercise, 28(8), 953-961.

Nosaka, K., Lavender, A., Newton, M., \& Sacco, P. (2003). Muscle damage in resistance training. International Journal of Sport and Health Science, 1(1), 1-8.

Ohman, E.M., Teo, K.K., Johnson, A.H., Collins, P.B., Dowsett, D.G., Ennis, J.T., \& Horgan, J.H. (1982). Abnormal cardiac enzyme responses after strenuous exercise: alternative diagnostic aids. British medical journal (Clinical Research Edition), 285(6354), 1523.

Ortega, E., Marchena, J.M., Garcia, J.J., Barriga, C., \& Rodriguez, A.B. (2005). Norepinephrine as mediator in the stimulation of phagocytosis induced by moderate exercise. European Journal of Applied Physiology, 93(5-6), 714-718.

Osgnach, C., Poser, S., Bernardini, R., Rinaldo, R., \& Di Prampero, P.E. (2010). Energy cost and metabolic power in elite soccer: a new match analysis approach. Medicine and Science in Sports and Exercise, 42(1), 170-178.

Pettersson, J., Hindorf, U., Persson, P., Bengtsson, T., Malmqvist, U., Werkström, V., \& Ekelund, M. (2008). Muscular exercise can cause highly pathological liver function tests in healthy men. British Journal of Clinical Pharmacology, 65(2), 253-259.

Philippou, A., Bogdanis, G., Maridaki, M., Halapas, A., Sourla, A., \& Koutsilieris, M. (2009). Systemic cytokine response following exercise-induced muscle damage in humans. Clinical Chemistry and Laboratory Medicine, 47(6), 777-782.

Pittman, R.N. (2016). Regulation of tissue oxygenation. (2 $2^{\text {nd }}$ ed.). In D.N. Granger \& J.P. Granger (Eds.), Colloquium lectures on integrated systems physiology: From molecule to function to disease (Lecture 65). Morgan \& Claypool Life Sciences.

Plaisance, E.P., \& Grandjean, P.W. (2006). Physical activity and high-sensitivity C-reactive protein. Sports Medicine, 36(5), 443-458.

Proske, U., \& Allen, T.J. (2005). Damage to skeletal muscle from eccentric exercise. Exercise and Sport Sciences Reviews, 33(2), 98-104.

Rampinini, E., Bosio, A., Ferraresi, I., Petruolo, A., Morelli, A., \& Sassi, A. (2011). Match-related fatigue in soccer players. Medicine and Science in Sports and Exercise, 43(11), 2161-2170.

Rosado, D.A.F. (2016). Immune cell changes in swimmers: Response to acute exercise and training (Doctoral dissertation, Universidade de Lisboa, Portugal).

Sabiston, C.M., Castonguay, A., Low, N.C., Barnett, T., Mathieu, M.E., O’Loughlin, J., \& Lambert, M. (2010). Vigorous physical activity and low-grade systemic inflammation in adolescent boys and girls. International Journal of Pediatric Obesity, 5(6), 509-515.

Sarmento, H., Marcelino, R., Anguera, M.T., Campanico, J., Matos, N., \& Leitao, J.C. (2014). Match analysis in football: a systematic review. Journal of Sports Sciences, 32(20), 1831-1843.

Schneider, B.S.P., \& Tiidus, P.M. (2007). Neutrophil infiltration in exercise-injured skeletal muscle. Sports Medicine, 37(10), 837-856.

Schoenfeld, B. (2016). Science and Development of Muscle Hypertrophy. Champaign, IL: Human Kinetics.

Shin, K.A., Park, K.D., Ahn, J., Park, Y., \& Kim, Y.J. (2016). Comparison of changes in biochemical markers for skeletal muscles, hepatic metabolism, and renal function after three types of long-distance running: Observational study. Medicine, 95(20), e3657.

Shin, Y.O., \& Lee, J.B. (2013). Leukocyte chemotactic cytokine and leukocyte subset responses during ultra-marathon running. Cytokine, 61(2), 364-369.

Silva, J.R., Ascensão, A., Marques, F., Seabra, A., Rebelo, A., \& Magalhães, J. (2013). Neuromuscular function, hormonal and redox status and muscle damage of professional soccer players after a high-level competitive match. European Journal of Aapplied Physiology, 113(9), 2193-2201. 
Silva, J.R., Rebelo, A., Marques, F., Pereira, L., Seabra, A., Ascensão, A., \& Magalhães, J. (2013). Biochemical impact of soccer: an analysis of hormonal, muscle damage, and redox markers during the season. Applied Physiology, Nutrition, and Metabolism, 39(4), 432-438.

Souglis, A., Bogdanis, G.C., Giannopoulou, I., Papadopoulos, C.H., \& Apostolidis, N. (2015). Comparison of inflammatory responses and muscle damage indices following a soccer, basketball, volleyball and handball game at an elite competitive level. Research in Sports Medicine, 23(1), 59-72.

Takahashi, I., Umeda, T., Mashiko, T., Chinda, D., Oyama, T., Sugawara, K., \& Nakaji, S. (2007). Effects of rugby sevens matches on human neutrophil-related non-specific immunity. British Journal of Sports Medicine, 41(1), 13-18.

Thorpe, R., \& Sunderland, C. (2012). Muscle damage, endocrine, and immune marker response to a soccer match. Journal of Strength and Conditioning Research, 26(10), 2783-2790.

Tidball, J.G. (2005). Inflammatory processes in muscle injury and repair. American Journal of Physiology-Regulatory, Integrative and Comparative Physiology, 288(2), R345-R353.

Urso, M.L., \& Clarkson, P.M. (2003). Oxidative stress, exercise, and antioxidant supplementation. Toxicology, 189(1), 41-54.

Varley, M.C., \& Aughey, R.J. (2013). Acceleration profiles in elite Australian soccer. International Journal of Sports Medicine, 34(01), 34-39.

Varley, M.C., Gregson, W., McMillan, K., Bonnano, D., Stafford, K., Modonutti, M., \& Di Salvo, V. (2016). Physical and technical performance of elite youth soccer players during international tournaments: influence of playing position and team success and opponent quality. Science and Medicine in Football, 2017, 1(1), 8-29.

Wittenberg, J.B., \& Wittenberg, B.A. (2003). Myoglobin function reassessed. Journal of Experimental Biology, 206(12), 2011-2020.

Submitted: February 12, 2017

Accepted: March 18, 2018

Published Online First: May 3, 2018

Correspondence to:

Branka Matković, Ph.D.

Faculty of Kinesiology, University of Zagreb

Horvaćanski zavoj 15

10000 Zagreb, Croatia

E-mail: bmatkovic@kif.hr

Phone: 00385-1- 3658666 